\title{
ATMOSPHERIC SYSTEM RESEARCH MARINE LOW CLOUDS WORKSHOP REPORT, JANUARY 27-29, 2016
}

Jensen, M., Wang, J., and Wood, R.

June 2016

Environmental \& Climate Sciences Dept.

Brookhaven National Laboratory

\author{
U.S. Department of Energy \\ Office of Science \\ Office of Biological and Environmental Research
}

Notice: This manuscript has been authored by employees of Brookhaven Science Associates, LLC under Contract No. DESC0012704 with the U.S. Department of Energy. The publisher by accepting the manuscript for publication acknowledges that the United States Government retains a non-exclusive, paid-up, irrevocable, world-wide license to publish or reproduce the published form of this manuscript, or allow others to do so, for United States Government purposes. 


\section{DISCLAIMER}

This report was prepared as an account of work sponsored by an agency of the United States Government. Neither the United States Government nor any agency thereof, nor any of their employees, nor any of their contractors, subcontractors, or their employees, makes any warranty, express or implied, or assumes any legal liability or responsibility for the accuracy, completeness, or any third party's use or the results of such use of any information, apparatus, product, or process disclosed, or represents that its use would not infringe privately owned rights. Reference herein to any specific commercial product, process, or service by trade name, trademark, manufacturer, or otherwise, does not necessarily constitute or imply its endorsement, recommendation, or favoring by the United States Government or any agency thereof or its contractors or subcontractors. The views and opinions of authors expressed herein do not necessarily state or reflect those of the United States Government or any agency thereof.. 


\section{Atmospheric System Research Marine Low Clouds Workshop Report}

\section{7-29 January 2016 Brookhaven National Laboratory}

Michael Jensen, Brookhaven National Laboratory

Jian Wang, Brookhaven National Laboratory

Robert Wood, University of Washington

Published June 2016

Work supported by the U.S. Department of Energy, Office of Science, Office of Biological and Environmental Research 


\section{Executive Summary}

Marine low clouds are a major determinant of the Earth's albedo and are a major source of uncertainty in how the climate responds to changing greenhouse gas levels and anthropogenic aerosol. Marine low clouds are particularly difficult to simulate accurately in climate models, and their remote locations present a significant observational challenge.

A complex set of interacting controlling processes determine the coverage, condensate loading, and microphysical and radiative properties of marine low clouds. Marine low clouds are sensitive to atmospheric aerosol in several ways. Interactions at microphysical scales involve changes in the concentration of cloud droplets and precipitation, which induce cloud dynamical impacts including changes in entrainment and mesoscale organization. Marine low clouds are also impacted by atmospheric heating changes due to absorbing aerosols. The response of marine low clouds to aerosol perturbations depends strongly upon the unperturbed aerosol-cloud state, which necessitates greater understanding of processes controlling the budget of aerosol in the marine boundary layer. Entrainment and precipitation mediate the response of low clouds to aerosols but these processes also play leading roles in controlling the aerosol budget.

The U.S. Department of Energy Atmospheric Radiation Measurement (ARM) Climate Research Facility and Atmospheric System Research (ASR) program are making major recent investments in observational data sets from fixed and mobile sites dominated by marine low clouds. This report provides specific action items for how these measurements can be used together with process modeling to make progress on understanding and quantifying the key cloud and aerosol controlling processes in the next 5-10 years. Measurements of aerosol composition and its variation with particle size are needed to advance a quantitative, process-level understanding of marine boundary-layer aerosol budget. Quantitative precipitation estimates that combine radar and lidar measurements are becoming available, and these could be used to test process models, quantify precipitation responses to aerosol, and constrain climate models. Models and observations can be used to constrain how clouds respond dynamically to changing precipitation. New measurements of turbulence from ground-based remote sensing could be used to attempt to relate entrainment to the vertical and horizontal structure of turbulence in the boundary layer. Cloud-top entrainment plays a major role in modulating how low clouds respond to both aerosols and to greenhouse gases, so investment in promising new observational estimates would be beneficial.

Precipitation formation and radiative cooling both help marine low clouds to organize on the mesoscale. More work is needed to develop metrics to characterize mesoscale organization, to elucidate mechanisms that determine the type and spatial scale of mesoscale cellular convection, and to understand the role of mesoscale structures in the stratocumulus-to-cumulus transition. 


\section{Acronyms and Abbreviations}

ACE-ENA

ARM

ASR

CAM5

CAP-MBL

CCN

3D

DOE

ENA

GASS

GCMs

GEWEX

GPCI

$\mathrm{K}$

$\mathrm{km}$

LES

LWP

MAGIC

MCC

$\mathrm{mm}$

PBL

POCs

SST

VAMOS

VOCALS

WGNE
Aerosol and Cloud Experiments in the Eastern North Atlantic campaign Atmospheric Radiation Measurement Climate Research Facility

Atmospheric System Research program

Community Atmospheric Model version 5

Clouds, Aerosol and Precipitation in the Marine Boundary Layer campaign

cloud condensation nuclei

three-dimensional

U.S. Department of Energy

Eastern North Atlantic, an ARM site in the Azores Islands

Global Atmospheric Systems Studies

global climate models

Global Energy and Water cycle Exchanges project

GEWEX/WGNE Pacific Cross-section Intercomparison project

Kelvin degrees

kilometer

large-eddy simulations

liquid water path

Marine ARM GPCI Investigation of Clouds campaign

mesoscale cellular convection

millimeter

planetary boundary layer

pockets of open cells

sea surface temperature

Variability of the American Monsoon Systems

VAMOS Ocean Cloud Atmosphere Land Study

Working Group for Numerical Experimentation, a World Meteorological Organization initiative 


\section{Contents}

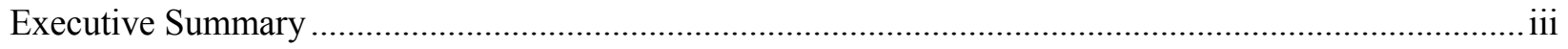

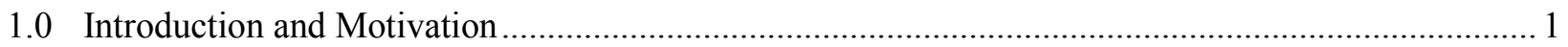

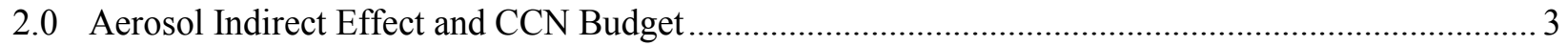

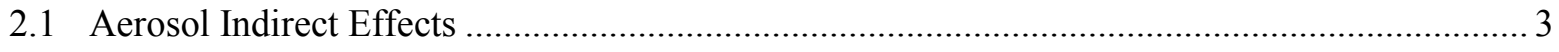

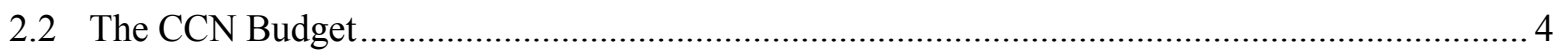

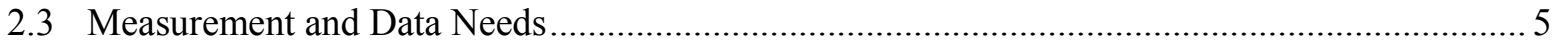

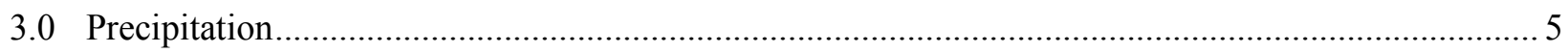

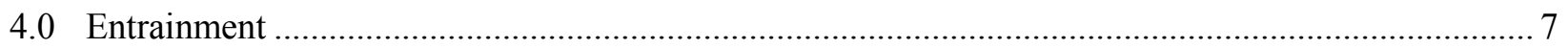

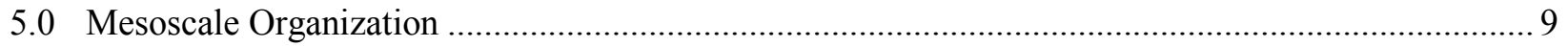

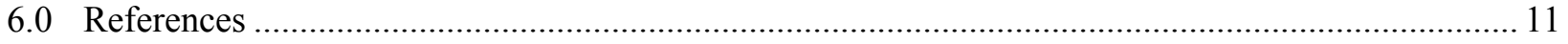

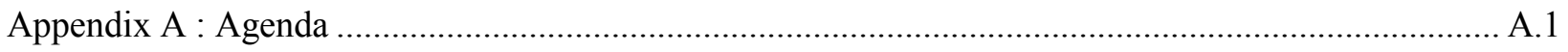

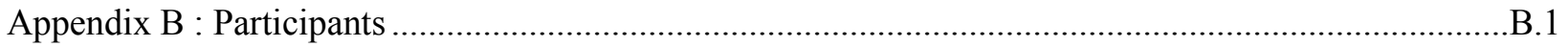

\section{Figures}

1. Front (L-R): Bretherton, Chris, Steve Krueger, Sandra Yuter, Virendra Ghate, David Painemal, Susannah Burrows. Back (L-R): Michael Jensen, Ann Fridlind, Pavlos Kollias, Rob Wood, Mark Miller, Sharon Zuhoski, Bob McGraw, Tony Del, Genio, Steve Ghan, Lynn Russell, Jian Wang, Shaima Nasiri, Paquita Zuidema.

\section{Tables}

1. Science questions relevant to the four theme areas discussed in this report. 


\subsection{Introduction and Motivation}

Marine low clouds have a significant impact on the Earth's energy and hydrologic cycle. They strongly reflect incoming solar radiation, with little compensating impact on outgoing longwave radiation, resulting in a net cooling of the atmospheric column (e.g., Wood 2012). Evaluation of climate model simulations has shown that the representation of marine low clouds represents one of the largest uncertainties in the estimation of climate sensitivity (e.g., Bony and Dufresne 2005). Marine low clouds are also critical mediators of global indirect radiative forcing (Zelinka et al. 2014). Despite the importance of these cloud systems to the Earth's climate, their representation in climate models is challenging, although incremental improvements are being made (Noda and Satoh 2014, Lauer and Hamilton 2013, Klein et al. 2013). These challenges are due to a combination of an incomplete understanding of the processes that regulate these clouds, and the lack of resolution of these processes, e.g., model grids are generally too coarse to adequately incorporate these processes. Boundary-layer processes that regulate marine low clouds (e.g., turbulent mixing, entrainment, radiative cooling, mesoscale organization, precipitation, and aerosol and cloud condensation nuclei [CCN] life cycles) occur at scales that demand much finer resolution grids for global climate models (GCMs), and some processes like cloud-top entrainment are poorly resolved even in extremely fine-resolution scales associated with large-eddy simulations (LES).

In order to help define research pathways to address some of the outstanding issues related to our understanding of marine low clouds, a workshop was held January 27-29, 2015 at Brookhaven National Laboratory. The overarching goal of this workshop was to identify and refine current gaps in our capability to understand or quantitatively simulate warm marine low-cloud properties and processes and develop strategies on how to address these gaps. A particular emphasis within this goal was the improvement of the representation of marine low clouds in climate models and contributions that can be made by DOE ASR researchers using ARM measurements and process modeling, e. g., using LES. The workshop focused on four main themes: 1) Aerosol Indirect Effects and the CCN Budget, 2)

Precipitation, 3) Entrainment and Mixing, and 4) Mesoscale Organization. The workshop concluded with a discussion on prioritization of the research topics, with a focus on which activities could lead to significant progress in understanding via ASR research and the use of ARM observations. Only those activities that were considered high priority are included in this workshop report. Specific science questions under each theme are presented in Table 1, along with a brief summary of approaches that can be used to address them.

Table 1. Science questions relevant to the four theme areas discussed in this report.

\begin{tabular}{|c|c|c|}
\hline Science theme & Science questions & $\begin{array}{c}\text { Action items for significant progress in 5- } \\
\text { to-10-year timeframe }\end{array}$ \\
\hline $\begin{array}{l}\text { Aerosol } \\
\text { indirect effects } \\
\text { and the } \mathrm{CCN} \\
\text { budget }\end{array}$ & $\begin{array}{l}\text { - Why do models produce such diversity in } \\
\text { the relationships driving aerosol effects on } \\
\text { cloud radiative forcing? } \\
\text { - How much do cloud-aerosol-precipitation } \\
\text { interactions-radiation vary in different } \\
\text { regions of the globe, and different cloud } \\
\text { and aerosol regimes? Which locations and } \\
\text { conditions show the greatest and least } \\
\text { sensitivity? }\end{array}$ & $\begin{array}{l}\text { - Determine the response of drizzle } \\
\text { formation to } \mathrm{N}_{\mathrm{d}} \text { and } \mathrm{CCN} \text { variations under } \\
\text { representative meteorological and clouds } \\
\text { conditions. } \\
\text { - Quantify the diversity in the relationship } \\
\text { between cloud radiative forcing and CCN } \\
\text { concentration among different models, } \\
\text { and the variation of the diversity with } \\
\text { region and meteorology }\end{array}$ \\
\hline
\end{tabular}




\begin{tabular}{|c|c|c|}
\hline Science theme & Science questions & $\begin{array}{c}\text { Action items for significant progress in 5- } \\
\text { to-10-year timeframe }\end{array}$ \\
\hline & $\begin{array}{l}\text { - What do we need to close the CCN } \\
\text { budget in marine boundary layer? }\end{array}$ & $\begin{array}{l}\text { - Observationally determine the } \\
\text { contributions of different aerosol sources } \\
\text { to MBL aerosol and the variations of the } \\
\text { contributions with season, and } \\
\text { meteorological and cloud conditions. } \\
\text { - Quantify aerosol and cloud properties, } \\
\text { and their controlling processes under } \\
\text { natural conditions. }\end{array}$ \\
\hline $\begin{array}{l}\text { Mesoscale } \\
\text { organization }\end{array}$ & $\begin{array}{l}\text {-What are the processes that drive } \\
\text { organization on the mesoscale in the } \\
\text { marine boundary layer and how do these } \\
\text { vary with MCC type? } \\
\text { - What variables are needed to characterize } \\
\text { and measure mesoscale organization? } \\
\text { - Is mesoscale organization secondary to } \\
\text { other processes? } \\
\text { - What is the relationship of precipitation to } \\
\text { the mesoscale organization? }\end{array}$ & $\begin{array}{l}\text { - Determine the extent to which the } \\
\text { inclusion of mesoscale variability of } \\
\text { marine low clouds in process models is } \\
\text { critical for determining cloud responses to } \\
\text { meteorological and climate forcing (e.g., } \\
\text { Sc-Cu transition, } \mathrm{CO}_{2} \text { and aerosol). } \\
\text { - Develop metrics that combine ground- } \\
\text { based and satellite remote sensing to } \\
\text { characterize mesoscale variability in } \\
\text { marine low-cloud systems. }\end{array}$ \\
\hline Entrainment & $\begin{array}{l}\text { - How can we better understand the relative } \\
\text { importance of radiative cooling and } \\
\text { buoyancy reversal as sources of Sc cloud- } \\
\text { top entrainment? } \\
\text { - Is there a way to constrain the magnitude } \\
\text { and importance of penetrative entrainment } \\
\text { at Cu cloud tops as a mechanism for } \\
\text { initiating Sc breakup? } \\
\text { - Are LES ready to be used to understand } \\
\text { variability within each regime along the } \\
\text { MAGIC transect and at the ENA? } \\
\text { - What are the roles of mixing, evaporation, } \\
\text { wind shear, and radiation on entrainment } \\
\text { efficiency (cloud top and lateral)? }\end{array}$ & $\begin{array}{l}\text { - Quantify the relationship between the } \\
\text { vertical and horizontal structure of } \\
\text { turbulence and entrainment rate in the } \\
\text { cloud-topped boundary layer. } \\
\text { - Determine the response of boundary layer } \\
\text { depth and related microphysical properties } \\
\text { of stratocumulus decks and trade cumulus } \\
\text { to a warming climate. } \\
\text { - Provide robust estimates of entrainment } \\
\text { rate for a variety of cloud conditions from } \\
\text { remote-sensing and aircraft observations. } \\
\text { - Quantify the impact of entrainment and } \\
\text { mixing processes on cloud microphysics. }\end{array}$ \\
\hline Precipitation & $\begin{array}{l}\text { - How much precipitation falls, how } \\
\text { frequently, from marine low clouds? } \\
\text { - What is the role of precipitation in } \\
\text { transitions in marine boundary-layer } \\
\text { clouds and in removing aerosol from the } \\
\text { MBL? } \\
\text { - Is removal of CCN by in-cloud accretion } \\
\text { and scavenging in the sub-cloud layer the } \\
\text { most important impacts of precipitation in } \\
\text { low clouds? } \\
\text { - What are the basic underlying physics that } \\
\text { produce the initial precipitation embryo? }\end{array}$ & $\begin{array}{l}\text { - Quantify climatology of precipitation rate } \\
\text { and condensate amount in and below } \\
\text { clouds from long-term ARM records. } \\
\text { - Determine role of precipitation in driving } \\
\text { cloud dynamical changes including cold } \\
\text { pools and cloudiness transitions. } \\
\text { - Combine LES modeling with new } \\
\text { observations to understand processes } \\
\text { driving the initiation of drizzle in marine } \\
\text { stratocumulus and cumulus clouds. } \\
\text { - Improve parameterizations of drizzle } \\
\text { formation to include impacts of } \\
\text { macroscale turbulence, mesoscale } \\
\text { organization, and giant CCN. }\end{array}$ \\
\hline
\end{tabular}




\subsection{Aerosol Indirect Effect and CCN Budget}

\subsection{Aerosol Indirect Effects}

Aerosols influence low clouds by changing the cloud droplet concentrations $\left(\mathrm{N}_{\mathrm{d}}\right)$, which in turn impact the cloud optical thickness even in the absence of cloud macrophysical changes. These optical thickness responses have been observed using ground-based and airborne sensors, with more carefully constrained studies increasingly documenting values near the theoretical maximum. However, changing $\mathrm{N}_{\mathrm{d}}$ also modifies the cloud droplet size distribution and therefore the efficiency of drizzle formation, which can alter the macrophysical properties of low clouds. Work in this area still needs to arrive at a consensus. In the last decade, numerous field observations and modeling studies have confirmed that drizzle is strongly susceptible to $\mathrm{N}_{\mathrm{d}}$ and $\mathrm{CCN}$ variations, but cloud responses to drizzle suppression are complex and sensitive to both meteorological and cloud conditions. Moreover, since aqueous chemistry in cloud droplets is a major source of sulfate mass, and drizzle is the dominant removal mechanism for $\mathrm{CCN}$, the feedback of clouds on CCN adds additional complexity.

A further observational challenge is the low-cloud response to absorbing aerosols. Shortwave-absorbing aerosols (primarily soot and dust) can decrease cloud fraction by warming the boundary layer and reducing its relative humidity. Other work links absorbing aerosols to reduced boundary-layer turbulent kinetic energy, reducing cloud-top entrainment and shallowing the boundary layer, thereby encouraging a higher relative humidity and cloud fraction. Absorbing aerosols located above the boundary layer can help stabilize the troposphere, increasing cloud fraction. Which of these diverse effects is dominant has not yet been established for the marine atmosphere above much of the world's oceans when such aerosols are present, with a first-order priority being to establish the relative vertical location of the absorbing aerosols and cloud structure.

In addition, studies suggest that the response of cloud to aerosol variation in the current climate, which can be constrained using present-day observations, may not accurately represent the responses of cloud and its radiative forcing to the increase of aerosol concentration due to anthropogenic emissions since the pre-industrial era (e.g., Penner et al. 2011, Ghan et al. 2016). Quantification of aerosol indirect effects therefore necessitates improved understanding of aerosol and cloud properties under pristine conditions.

Given that a large fraction of the uncertainty of modeled aerosol indirect forcing is due to the uncertainties in aerosol and cloud processes that were parameterized for pre-industrial natural conditions, marine low-cloud responses to CCN concentration in GCMs will similarly exhibit significant uncertainty in both today's and the future climate. Uncertainties are further exacerbated by recent research that demonstrates that the relationship between cloud radiative forcing and $\mathrm{CCN}$ concentration is driven by a range of interconnected processes, and simulations under present climatic conditions reveal a large diversity in this relationship among different models (Ghan et al. 2016). On the other hand, the cloud radiative forcing, which is well constrained by satellite measurements, is largely in agreement among models, at least at the global scale. However, models have very different responses of $\mathrm{Nd}$ to the variation of CCN concentration, in part because of the difference in, or absence of, a lower bound of Nd that is applied (Hoose et al. 2009). The Community Atmospheric Model ver. 5 (CAM5) does not apply a lower bound, and exhibits the highest sensitivity of Nd to CCN concentration (Ghan et al. 2016). Models also exhibit very different sensitivities of cloud radiative forcing to $\mathrm{Nd}$, largely due to the diversity in the response of the liquid water path (LWP) to Nd. This diversity appears to be strongly affected by the 
susceptibility of warm rain to $\mathrm{Nd}$ in models (Wang et al. 2012), and it may be driven by uncertainty in how to represent warm rain processes (e.g., using different approaches that describe autoconversion/accretion formulations) in GCMs.

Currently there is a lack of systematic examination of these warm rain processes, especially their variation in different regions of the globe, and under different cloud and aerosol regimes. The representation of these processes in GCMs needs to be better constrained using comprehensive measurements, especially in regions where models exhibit the largest diversities, in order to gain confidence in the model estimates of aerosol indirect effects. Model assessment studies guided by observations (e.g., Global Atmospheric Systems Studies [GASS] and VAMOS Ocean Cloud Atmosphere Land Study [VOCALS]) have helped to identify areas needing improvement for LES and GCMs in marine low-cloud regimes. For GCMs, the free-tropospheric aerosol distribution, simulation of the cloud macrophysical properties, and aerosolprecipitation interactions are challenges. LES microphysical schemes also produce a range of precipitation rates for a given aerosol concentration and cloud layer thickness. Continued strong support for such coordinated model assessment activities is encouraged.

\subsection{The CCN Budget}

Remote marine low-cloud systems are particularly susceptible to perturbations in aerosols associated with anthropogenic emissions because of their relatively low optical thickness and low background aerosol concentrations. Given the large spatial coverage of marine low clouds, accurate assessment of the aerosol indirect forcing necessitates a predictive understanding of the CCN budget in the marine boundary layer, under both pre-industrial and current climatic conditions. This budget has barely been diagnosed in most CMIP5 climate models, let alone assessed against credible observational estimates in different cloud regimes and regions. The $\mathrm{CCN}$ population is driven by a range of processes, including generation of spray aerosol through breaking waves via bubble bursting, entrainment of free tropospheric aerosol (the key pathway for anthropogenic aerosol influence on remote marine low clouds), and removal of aerosol particles by drizzle. LES and ship observations also suggest that under certain conditions (i.e., strongly precipitating organized open cellular convection), nucleation from the gas phase in the boundary layer may also be a significant source of small aerosols that can grow to become CCN. In such conditions, aerosol concentrations can also be 1-2 orders of magnitude lower in the overlying stratocumulus cloud layer compared with the sub-cloud/surface layer, so the aerosol profile is as important to simulate as the boundary layer mean aerosol concentration.

We currently lack a quantitative understanding of some of these key processes, including the scavenging of CCN by coalescence of cloud droplets, as well as marine biogenic aerosol emission and its variation with wind speed, biological activity, and sea-surface temperature. Observations clearly prove that for a given amount of condensate, higher aerosol loadings are associated with reduced precipitation from low clouds (e.g. Mann et al. 2014). However, we also know that coalescence of drops removes aerosol number concentration, and calculations suggest that precipitation rates as low as $1 \mathrm{~mm} /$ day are sufficient to exert a first-order impact on aerosol number concentration in the boundary layer. Thus, it may be difficult to ascertain the extent of process interdependencies in the face of such potential for two-way interactions between aerosols and precipitation.

Several LES models now operate with fully interactive aerosol processes (e. g., Kazil et al. 2011, Berner et al. 2013) and show skill in simulating observed phenomena such as "pockets of open cells" (POCs) and 
ship tracks. However, they still rely on parameterizations of cloud microphysics, aerosol nucleation, and aerosol sources and loss processes that need better observational testing. As aerosol-coupled LES develop quantitative credibility, these could be used together with aircraft studies to constrain and understand the key processes controlling the CCN budget and to inform GCM parameterization development and testing.

\subsection{Measurement and Data Needs}

Advances in scientific understanding of aerosol and cloud processes and validation of their representations in models will require comprehensive measurements both at long-term sites and in aircraft-based studies. The data sets gathered from the Marine ARM GPCI Investigation of Clouds (MAGIC) campaign, the Clouds, Aerosol and Precipitation in the Marine Boundary Layer (CAP-MBL) campaign, and from the Eastern North Atlantic (ENA) site address some of these observational needs well. However, measurements of aerosol composition and its variation with particle size are scarce, and these are needed to advance a quantitative, process-level understanding and characterization of marine boundary layer aerosol sources. It is also important to focus efforts on producing derived products - most importantly, surface-derived precipitation rate and its vertical profile, in conjunction with cloud microphysical properties and the vertical structure of cloud-forming aerosol. In addition, vertical and horizontal variations of trace gases, aerosol, and cloud fields from aircraft-based studies, such as the upcoming Aerosol and Cloud Experiments in the Eastern North Atlantic (ACE-ENA) campaign, are needed to examine the key processes, constrain model simulations, and provide validation of surfacebased remote-sensing estimates. The aerosol and cloud properties under pristine conditions need to be better understood, and this requires field observations in regions where the anthropogenic impact is minimal and pristine conditions are more prevalent. These needs are being addressed by recent and upcoming field campaigns focusing on the Amazon basin and Southern Ocean.

\section{Action items for significant progress in the next five to ten years:}

1. Determine the response of drizzle formation to $\mathrm{Nd}$ and $\mathrm{CCN}$ variations under representative meteorological and cloud conditions.

2. Quantify the diversity in the relationship between cloud radiative forcing and $\mathrm{CCN}$ concentration among different models, and the variation of the diversity with region and meteorology.

3. Observationally determine the contributions of different aerosol sources to MBL aerosol and the variations of the contributions with season and meteorological and cloud conditions.

4. Quantify aerosol and cloud properties, and their controlling processes under natural conditions.

\subsection{Precipitation}

Marine low clouds appear to precipitate more readily than those over land, in part because cloud droplet concentrations are much lower over oceans where there is a lower availability of cloud-forming aerosol. The increased use of millimeter radars over the last two decades has played a critical role in showing that marine low clouds precipitate frequently. However, conventional methods (e.g., disdrometers, rain gages) for quantifying precipitation rate are inadequate for observing the light precipitation associated with planetary boundary layer (PBL) clouds. Thus the rates at which marine low clouds precipitate remains poorly quantified. A considerable fraction of the precipitation falling from low clouds evaporates before 
reaching the surface (Comstock et al. 2004, Wood 2005), making the quantification of precipitation in such clouds strongly sensitive to the distance below cloud. Metrics to quantify marine low-cloud precipitation do not yet recognize this, in part because the amount of evaporation is important in the assessment of impacts upon boundary-layer moisture and energy budgets, upon cold pool formation, and upon aerosol scavenging. Approaches that combine radar and lidar retrieval data are able to more accurately constrain the size distribution of precipitation below cloud and therefore quantify how this size distribution evolves as it falls below cloud. Although these techniques require further refinement and validation, existing retrieval methods can be used to generate much needed products from existing ARM data records (e.g., from MAGIC, ENA).

Significantly more precipitation is capable of reaching the surface in deeper shallow cumulus (Snodgrass et al. 2009), and can play a first-order role in controlling the PBL moisture budget. The formation of cold pools from evaporating precipitation from low clouds appears to be a relatively common occurrence. Observational evidence points to a role in initiating and organizing new convection for the subset of stronger, deeper cold pools that have sufficiently strong and deep updrafts at their leading edge to reach near-cloud level. Large-domain LES modeling, as well as nested-WRF simulations able to incorporate large-scale forcing, in conjunction with new scanning measurements such as X-band radar and Doppler lidar, will help identify the relative roles of the diurnal cycle, precipitation, and cold pools on transitions and cloud organization.

A longstanding problem in understanding the formation of warm rain in marine low clouds is in understanding the initiation of drizzle. Condensational growth slows as droplet size increases, but the collision efficiency for small drops is small, leading to a significant barrier to the formation of precipitation. Understanding the rate of formation of a relatively small number of "lucky" precipitation embryos requires an understanding of the physics driving the tail of the droplet distribution, which is challenging to measure well and to predict theoretically. Supersaturation fluctuations, giant CCN, and spectra broadening due to entrainment and mixing have all been proposed as ways to bridge the drizzle barrier. New observational approaches are emerging that can quantify giant $\mathrm{CCN}$, and measure the cloud droplet size distribution at the relevant scales for understanding microscale turbulent fluctuations and the impacts of entrainment and mixing. The radar Doppler spectrum indicates that the initiation of drizzle begins at much lower radar reflectivity than one typically associates with the presence of drizzle below cloud base. Using the radar Doppler information to probe drizzle initiation in combination with process models such as simple 1D models and LES (both with bin and bulk schemes), as well as the multiscale modeling approaches mentioned in the previous section, could provide desperately needed information to better understand drizzle initiation.

The interdependence of precipitation with the type and distribution of aerosol appears to exert a strong control on the strength of the cloud lifetime effect (second aerosol indirect effect) in large-scale models. Most climate models represent collision-coalescence processes using bulk representations (e.g., autoconversion, accretion) that may build in an artificially strong sensitivity to aerosol. Observational constraints on these bulk rates can be derived from in situ observations of the drop size distribution. However, constraints from multiple wavelength Doppler radar, in conjunction with visible and passive microwave measurements, can help to constrain the rates of conversion of cloud droplets to drizzle drops, as well as help to determine the sensitivity of bulk microphysical parameterizations to cloud droplet concentration, and, ultimately, to aerosol. 
From the modeling perspective, precipitation from boundary-layer cloud is important mainly because of its strong interaction with other cloud-controlling factors, rather than due to its contribution to surface rainfall. Precipitation, aerosol, mesoscale variability, entrainment, boundary-layer vertical structure, and cloud properties are inextricably interdependent. A large-domain LES can explicitly simulate the mesoscale and turbulence-scale circulations that support these linkages, so it is an exciting tool for comparison with the new radar and in situ observations that sample small-scale variability in precipitation and its relation to other cloud and boundary-layer properties. However, these processes are on the subgrid scale of most current GCMs, making the parameterization of precipitation-related processes particularly challenging until the grid resolution of such models decreases to below $10 \mathrm{~km}$ and begins to capture more of the observed variability in precipitation from boundary-layer clouds.

\section{Action items to achieve significant progress in the next five to ten years:}

1. Quantify climatology of precipitation rate and condensate amount in and below clouds from longterm ARM data records.

2. Determine role of precipitation in driving cloud dynamical changes, including cold pools and cloudiness transitions.

3. Combine LES modeling with new observations to understand processes driving the initiation of drizzle in marine stratocumulus and cumulus clouds.

4. Improve parameterizations of drizzle formation to include impacts of macroscale turbulence, mesoscale organization, and giant $\mathrm{CCN}$.

\subsection{Entrainment}

A large part of the range of GCM estimates of climate sensitivity and cloud feedback arises from differences in process parameterizations and model simulations of the stratocumulus decks in, e.g., trade cumulus regions. In stratocumulus-dominated regions, model feedbacks differ according to the competition between processes that thicken boundary-layer clouds in a warming climate; these include, e.g., weakening large-scale subsidence and stronger entrainment, or weakening entrainment due to a stronger inversion. In addition, feedbacks include processes that make boundary-layer clouds thinner with warming, via an increased vertical moisture gradient that allows a thinner cloud to maintain the same entrainment, or a more emissive free troposphere that produces less cloud-top turbulent mixing, or drying by shallow cumulus that penetrate the stratocumulus cloud top (Bretherton et al. 2014, Zhang et al. 2013). In trade cumulus regions, some GCMs produce a stratocumulus deck near the cumulus cloud base that is not observed (Nuijens et al. 2015). Those GCMs that do not produce a stratocumulus deck near cloud base may sometimes accomplish this by artificially enforcing a choice of one cloud type or the other rather than producing this result naturally by accurate regulation of PBL depth via entrainment and the mass sink by cumulus. The ability of models to prevent stratocumulus occurrence in trade cumulus regions may be of broader importance, e.g., with significant influence on the calculated climate sensitivity (Brient et al. 2016).

Especially for stratocumulus, cloud-top entrainment of free tropospheric air is a key process that determines the vertical extent of the clouds and influences their areal coverage. An inversion atop stratocumulus is constantly sharpened by strong longwave cooling of the underlying stratocumulus cloud 
tops, and can encompass $10 \mathrm{~K}$ of temperature change in as little as $10 \mathrm{~m}$. Thus GCMs cannot resolve the inversion layer atop stratocumulus using the current paradigm for defining and applying grid sizes, and even LES must use grid spacings of less than $10 \mathrm{~m}$ to minimize pitfalls such as excessive entrainment due to numerical diffusion.

In a cloud-free convective boundary layer, the entrainment rate is known to be proportional to the boundary-layer turbulent kinetic energy production rate (driven by surface heat fluxes under low-windshear conditions) divided by the inversion virtual temperature jump. However, clouds greatly complicate this simple picture because: first, the latent heating due to cloud condensation and evaporation affects the structure of the turbulence and the cloud-top entrainment layer and, second, longwave cooling and shortwave heating within clouds strongly modulate the driving of turbulence.

For a given intensity of cloud-layer turbulence, the humidity difference across the inversion, the mean wind shear, and even the cloud droplet size all appear to affect entrainment in ways that remain controversial despite decades of investigations. The appropriate way to relate entrainment rate to the vertical and horizontal structure of turbulence in a cloudy boundary layer is also still debated. Together, these two issues make 'entrainment closure' a major uncertainty in GCM parameterizations.

LES models represent a very useful but imperfect tool for studying entrainment and its effects in cloudy boundary layers. Intercomparison studies have shown that even with vertical grid spacings as small as 5 $\mathrm{m}$, LES of entrainment rate is still somewhat sensitive to the choice of advection scheme and sub-grid turbulence parameterization, as well as the vertical and horizontal grid. In addition, assumptions made in the bulk microphysical schemes used in most LES, such as the instantaneous evaporation of cloud droplets in subsaturated conditions, may be less accurate in the highly inhomogeneous conditions of the entrainment zone, with consequences for the simulated entrainment rate. In order to gain more confidence in the representation of cloud-top processes in LES, there is a need to use both ground- and satellite-based observations to identify relatively stationary boundary-layer conditions for model testing and intercomparison.

The estimation of entrainment rate from ground-based remote sensing and in situ (aircraft) measurements to provide observational constraints for models remains a significant challenge. Individual entrainment events occur on spatial scales that are smaller than the resolution attainable by most remote-sensing instruments. These difficulties raise the question of whether we can observationally estimate the entrainment rate as a function of cloud and environmental state quantities with sufficient accuracy to constrain models. Several promising techniques to estimate entrainment rates and the turbulent processes controlling them have been developed using vertically pointing cloud radar observations (Albrecht et al. 2016) and aircraft observations (e.g., Lu et al. 2012). These techniques need to be applied to long-term observations at the ARM sites, and compared and vetted against each other and model simulations.

The impact of entrainment and subsequent mixing on the cloud droplet size distribution has important impacts and feedbacks on the cloud dynamics, radiative impacts, and life cycle. These impacts depend on the mixing scenario (homogeneous or inhomogeneous), which is controlled by numerous factors, including the properties of the entrained air (e.g., temperature, relative humidity, CCN concentration, entrainment fraction), the turbulent kinetic energy dissipation rate, and the cloud particle size distribution. Most GCMs and LESs assume homogeneous rather than inhomogeneous mixing despite the fact that recent measurements (Beals et al. 2015) indicate that mixing is generally strongly inhomogeneous. An improved understanding of the mixing process and its impact on cloud microphysics will require a 
combination of targeted aircraft observations and small-scale modeling studies (LES, direct numerical simulation or multiscale modeling approaches based on representing all relevant scales of entrainment, turbulent mixing, and droplet growth in one dimension), and advances in remote-sensing measurement and retrieval techniques. New airborne instrumentation (e.g., droplet holography) is available to constrain small-scale turbulent mixing processes, although existing aircraft data sets can also be exploited further.

\section{Action items to achieve significant progress in the next five to ten years:}

1. Quantify the relationship between the vertical and horizontal structure of turbulence and entrainment rate in the cloud-topped boundary layer.

2. Determine the response of boundary-layer depth and related macrophysical properties of stratocumulus decks and trade cumulus to a warming climate.

3. Provide robust estimates of entrainment rate for a variety of cloud conditions from remote-sensing and aircraft observations.

4. Quantify the impact of the entrainment and mixing process on cloud microphysics.

\subsection{Mesoscale Organization}

Marine low-cloud fields display coherent mesoscale organization on horizontal scales of 5-100 km. Mesoscale regions of three-dimensional (3D) cells are described as mesoscale cellular convection (MCC, Atkinson and Zhang 1996) and can occur as groupings of open and closed cells. Mesoscale structures organize the internal diabatic forcings on the PBL (e.g., precipitation, latent heat release) and these forcings play a role in mesoscale dynamical motions that modulate liquid water path, albedo, and cloud cover. External perturbations including advection and gravity waves also play a role in modulating low cloud cover. While some numerical studies show a causative relation between areal cloudiness and internal variations in precipitation and aerosol, observational evidence based on recent field programs and satellite data sets does not show clear attribution. Current global climate models have difficulty representing basic areal mean characteristics of low marine clouds including cloud height, cloud depth, liquid water path and the diurnal variation of these quantities. Current sub-grid parameterizations of boundary-layer cloud generally do not explicitly account for mesoscale variability, even though its scale is below the $100 \mathrm{~km}$ grid scale of many climate models. LES models used for simulating cloudy boundary layers and their response to climate and aerosol perturbations are more often than not run on domains less than $10 \mathrm{~km}$ on a side, which exclude mesoscale processes. It is an open and important question whether simulation of mesoscale organization would fundamentally change any conclusions of such models.

Key processes controlling MCC are not well understood. Mesoscale organization is seen in almost all marine low-cloud fields, stratiform or cumuliform, precipitating or nonprecipitating. Precipitation seems to enhance cellularity and increase its scale through cold pool generation, but the interactions between MCC, precipitation, and atmospheric aerosol are not well quantified. Knowledge and understanding of the physics of MCC may be needed to accurately represent marine low clouds in climate models. The horizontal scales of MCC present a significant modeling challenge to GCMs, as the dominant scales are comparable to the horizontal resolution in the next generation of climate models. They are also a challenge to LES, because of the need for a large grid to span between turbulent eddy scales of $100 \mathrm{~m}$ or less and the 50-100 km-wide domain size needed to capture the mesoscale organization, as well as a 
simulation of many hours to days to evolve this organization. Nevertheless, LES are being used to successfully simulate MCC in stratocumulus, shallow cumulus, and cold-air outbreaks and show much promise in this context as a useful intermediary between in situ observations and climate models.

Transitions in mesoscale cloud structure are also embedded in the stratocumulus-to-cumulus ( $\mathrm{Sc}-\mathrm{Cu})$ transition; and these transitions strongly influence the albedo of the tropical oceans. Mesoscale cloud variability is ubiquitous within the transition region, where cumulus rise up into patches of overlying stratocumulus. Precipitation from these cumulus can drive cold pool formation that may help organize MCC. LES suggests that latent heating released by precipitation in regions of $\mathrm{Cu}$ and thicker $\mathrm{Sc}$ helps drive upward motion in those regions, driving mesoscale circulations. The $\mathrm{Sc}-\mathrm{Cu}$ transition is currently understood in terms of small-scale processes driven by increasing latent heat flux and boundary-layer deepening over warmer sea surface temperatures (SST, Bretherton and Wyant 1997).

Despite the fact that the $\mathrm{Sc}-\mathrm{Cu}$ transition involves mesoscale dynamics, a systematic exploration of the extent to which the explicit representation of mesoscale organization would help more accurately simulate the $\mathrm{Sc}-\mathrm{Cu}$ transition has not yet been carried out. Large-domain LES as well as nested-WRF simulations offer opportunities to critically test hypotheses regarding the importance of mesoscale processes for controlling cloud radiative properties. The ENA site experiences mesoscale variability of clouds that are in part associated with large scale synoptic advection associated with extratropical cyclones. LES modeling studies have shown qualitatively convincing representations of the mesoscale variability of marine low clouds. However, little quantitative assessment of the realism of the simulations using observed mesoscale variability has been carried out. For LES this requires large domains of $100+\mathrm{km}$ on a side that are large enough to represent cloud variability on scales of $10+\mathrm{km}$ while maintaining adequate grid resolution to simulate cloud-turbulence interaction. LES modeling intended for comparison with long-term ENA observations (not Lagrangian) will likely be incomplete without accounting for substantial horizontal variability in cloudiness associated with synoptic advection. A combination of LES and mesoscale models is therefore likely needed. The sensitivity to microphysical representation is also an issue.

There is currently no consensus on how to define and characterize MCC in observations and in models that are able to resolve the relevant scales. Surprisingly little is known about the spatial scale and organization of updrafts in MCC, although previous work has demonstrated marked mesoscale variability in horizontal winds in MCC. Ground-based remote-sensing techniques such as scanning and vertically pointing Doppler radars and lidar offer new ways to probe mesoscale structure and dynamics, and continuous monitoring of PBL thermal and moisture structure (e.g., with spectral infrared and lidar-based approaches) will help connect mesoscale cloud structure and dynamics to the vertical thermodynamic structure of the marine PBL. Although observations are becoming available to address this, significant additional effort will be needed to generate products that the ASR scientific community will need for statistically robust analyses. Examples pertinent to understanding MCC structure include derived water vapor and temperature profiles using Raman lidar and passive hyperspectral infrared radiometers; condensate estimates that can separate cloud and precipitation; and scanning radar Doppler winds. Combining these ground-based views with broader-scale satellite data will provide insight into the structure and dynamics of MCC and how it impacts cloudiness transitions.

A close association has been observed between clear areas between clouds in open cell MCC and very low aerosol concentrations. LES studies suggest that the open or closed cellular form of MCC and therefore albedo may be strongly sensitive to perturbations in aerosol. However, LES studies also show 
that the condensation and precipitation of open cells are effective at removing aerosol from the PBL. Thus MCC may engender its own aerosol environment (Berner et al. 2013) such that the observed correlations between aerosol and MCC type might be less indicative of a sensitivity of MCC to aerosol than they are of a sensitivity of aerosol to MCC type. Aircraft observations will continue to be important for providing the aerosol and cloud microphysical data needed to quantify the direction of causality in interactions between aerosol and mesoscale cloud organization. Observations and associated modeling from VOCALS highlighted the importance of aerosol scavenging from drizzle in tropical stratocumulus, and demonstrated a tight connection between the type of mesoscale organization and CCN concentrations, but it is not yet clear whether these connections are more generalizable to other regions, especially the extratropics.

\section{Action items to achieve significant progress in the next five to ten years:}

1. Determine the extent to which the inclusion of mesoscale variability of marine low clouds in process models is critical for determining cloud responses to meteorological and climate forcing (e.g., $\mathrm{Sc}-\mathrm{Cu}$ transition, $\mathrm{CO}_{2}$ and aerosol)

2. Develop metrics that combine ground-based and satellite remote sensing to characterize mesoscale variability in marine low-cloud systems.

\subsection{References}

Albrecht, BA, M Fang, and V. Ghate. 2016. "Exploring stratocumulus cloud-top entrainment processes and parameterizations by using Doppler cloud radar observations." Journal of the Atmospheric Sciences 73: 729-742, doi:10.1175/JAS-D-15-0147.1.

Atkinson, BW, and J Wu Zhang. 1996. "Mesoscale shallow convection in the atmosphere." Reviews of Geophysics 34(4): 403-31, doi:10.1029/96RG02623.

Beals, MJ, JP Fugal, RA Shaw, J Lu, SM Spuler, and JL Stith. 2015. "Holographic measurements of inhomogeneous cloud mixing at the centimeter scale." Science 350(6256): 87-90, doi:10.1126/science.aab0751.

Berner, AH, CS Bretherton, R Wood, and A Muhlbauer. 2013. "Marine boundary layer cloud regimes and POC formation in a CRM coupled to a bulk aerosol scheme." Atmospheric Chemistry and Physics 13(24): 12549-72, doi:10.5194/acp-13-12549-2013.

Bony, S, and J-L Dufresne. 2005. "Marine boundary layer clouds at the heart of tropical cloud feedback uncertainties in climate models." Geophysical Research Letters 32(20): L20806.

doi:10.1029/2005GL023851.

Brient, F, T Schneider, Z Tan, S Bony, X Qu, and A Hall. 2016: "Shallowness of tropical low clouds as a predictor of climate models' response to warming." Climate Dynamics doi:10.1007/s00382-015-2846-0.

Bretherton, CS, and MC Wyant. 1997. "Moisture transport, lower-tropospheric stability, and decoupling of cloud-topped boundary layers." Journal of the Atmospheric Sciences 54(1): 148-67, doi:10.1175.15200469(1997)054<0148MTLTSAQ $>2.0 . \mathrm{CO} ; 2$. 
Bretherton, CS, and PN Blossey. 2014. "Low cloud reduction in a greenhouse-warmed climate: Results from Lagrangian LES of a subtropical marine cloudiness transition." Journal of Advances in Modeling Earth Systems 6(1): 91-114, doi:10.1002/2013MS000250.

Comstock, KK, R Wood, SE Yuter, and CS Bretherton. 2004. "Reflectivity and rain rate in and below drizzling stratocumulus." Quarterly Journal of the Royal Meteorological Society 130(603): 2891-2918, doi:10.1256/qj.03.187.

Ghan, S, M Wang, S Zhang, S Ferrachat, A Gettelman, J Griesfeller, Z Kipling, U Lohmann, H Morrison, D Neubauer, DG Partridge, P Stier, T Takemura, H Wang, and K Zhang. 2016. "Challenges in constraining anthropogenic aerosol effects on cloud radiative forcing using present-day spatiotemporal variability." Proceedings of the National Academy of Sciences of the United States of America 113(21): 5804-5811, doi:10.1073/pnas.1514036113.

Hoose, C, JE Kristjansson, T Iversen, A Kirkevag, O Seland, and A Gettleman. 2009. "Constraining cloud droplet number concentration in GCMs suppresses the aerosol indirect effect." Geophysical Research Letters 36(12), doi:10.1029/2009GL038568.

Kazil, J, H Wang, G Feingold, AD Clarke, JR Snider, and AR Bandy. 2011. "Modeling chemical and aerosol processes in the transition from closed to open cells during VOCALS-REx." Atmospheric Chemistry and Physics 11(15): 7491-7514, doi:10.5194/acp-11-7491-2011.

Klein, SA, Y Zhang, MD Zelinka, R Pincus, J Boyle, and PJ Gleckler. 2013. "Are climate model simulations of clouds improving? An evaluation using the ISCCP Simulator." Journal of Geophysical Research: Atmospheres 118(3): 1329-42, doi:10.1002/jgrd.50141.

Lauer, A, and K Hamilton. 2013. "Simulating clouds with global climate models: A comparison of CMIP5 results with CMIP3 and satellite data." Journal of Climate 26(11): 3823-45, doi:10.1175/JCLI-D$\underline{12-00451.1 .}$.

Lu, C, Y Liu, S Niu, and AM Vogelmann. 2012. "Lateral entrainment rate in shallow cumuli: Dependence on dry Air sources and probability density functions." Geophysical Research Letters 39(20): L20812, doi:10.1029/2012GL053646.

Mann, JAL, JC Chiu, RJ Hogan, EJ O'Connor, TS L'Ecuyer, THM Stein, and A Jefferson. 2014. "Aerosol impacts on drizzle properties in warm clouds from ARM Mobile Facility maritime and continental deployments." Journal of Geophysical Research: Atmospheres 11(7): 4136-4148, doi:10.1002/2013JD021339.

Noda, AT, and M Satoh. 2014. "Intermodel variances of subtropical stratocumulus environments simulated in CMIP5 models." Geophysical Research Letters 41(21): 7754-7761, doi:10.1002/2014GL061812.

Nuijens, L, B Medeiros, I Sandu, and M Ahlgrimm. 2015. "The behavior of trade-wind cloudiness in observations and models: The major cloud components and their variability." Journal of Advances in Modeling Earth Systems 7(2): 600-616, doi:10.1002/2014MS000390. 
Penner, JE, L Xu, and M Wang. 2011. "Satellite methods underestimate indirect climate forcing by aerosols." Proceedings of the National Academy of Sciences of the United States of America 108(33): 13404-13408, doi:101073/pnas.1018526108.

Snodgrass, ER, L Di Girolamo, and RM Rauber. 2009. "Precipitation characteristics of trade wind clouds during RICO derived from radar, satellite, and aircraft measurements." Journal of Applied Meteorology and Climatology 48(3): 464-83, doi:10.1175/2008JAMC1946.1.

Wang, M, S Ghan, X Liu, TS L'Ecuyer, K Zhang, H Morrison, M Ovchinnikov, R Easter, R Marchand, D Chand, Y Qian, and JE Penner. 2012. "Constraining cloud lifetime effects of aerosols using A-Train satellite observations.” Geophysical Research Letters 39(15), doi:10.1029/2012GL052204.

Wood, R. 2005. "Drizzle in stratiform boundary layer clouds. Part I: Vertical and horizontal structure." Journal of the Atmospheric Sciences 62(9), doi:10.1175/JAS3529.1.

Wood, R. 2012. "Stratocumulus clouds." Monthly Weather Review 140(8): 2373-2423, doi:10.1175/MWR-D-11-00121.1.

Zelinka, MD, T Andrews, PM Forster, and KE Taylor. 2014. "Quantifying components of aerosol-cloudradiation interactions in climate models." Journal of Geophysical Research: Atmospheres 119(12): 75997615, doi:10.1002/2014JD021710.

Zhang, M, CS Bretherton, PN Blossey, PH Austin, JT Bacmeister, S Bony, F Brient, SK Cheedela, A Cheng, AD Del Genio, SR De Rode, S Endo, CN Franklin, J-C Golaz, C Hannay, T Heus, FA Isotta, J-L Dufresne, I-S Kang, H Kawai, M Kohler, VE Larson Y Liu, AP Lock, U Lohmann, MF Khairoutdinov, AM Molod, RAJ Neggers, P Rasch, I Sandu, R Senkbeil, AP Siebesma, C Siegenthaler-Le Drian, B Stevens, MJ Suarez, K-M Xu, K von Salzen, MJ Webb, A Wolf, and M Zhao. 2013. "CGILS: Results from the first phase of an international project to understand the physical mechanisms of low cloud feedbacks in single column models." Journal of Advances in Modeling Earth Systems 5(4): 826-42, doi:10.1002/2013MS000246. 


\section{Appendix A: Agenda}

ASR Marine Low Clouds Workshop at Brookhaven National Laboratory

Location: Building 490 Large Conference Room

Wednesday, January 27

9:30 AM -10:00 AM Check-in, Logistics and Continental Breakfast (Included)

10:00 - 10:30 AM Introduction and Meeting Goals

10:30 - noon $\quad$ Plenary \#1 (2 talks)

Rob Wood - Aerosol indirect effect + CCN budget

Sandra Yuter - Mesoscale organization

noon - 1:15 PM Lunch at Berkner (not included)

1:15 - 3:30 PM Breakouts \#1

Steve Ghan - Aerosol Indirect Effects + CCN budget

Mike Jensen - Mesoscale Organization and its effect on cloud

AIE: Burrows, Fridlind, Ghan, McGraw, Painemal, Russell, Wang, Wood, Zuidema

MO: Bretherton, Del Genio, Ghate, Jensen, Kollias, Krueger, Miller, Yuter

3:30 -3:45 PM Coffee break (included)

3:45-4:15 PM Debrief

4:15 - 5:30 PM Group Discussion(s)

Discussion of modeling needs

5:30 - 8:00 PM Dinner (offsite, not included)

Thursday, January 28

9:00 - 9:30 AM Continental Breakfast (included)

9:30 - 10:00 AM Review of Day 1 Discussions 

10:00 - 11:45 AM Plenary \#2
Tony Del Genio - Entrainment and Mixing
Pavlos Kollias - Precipitation

11:45 AM - 1:15 PM Lunch at Berkner (not included)

1:15 - 3:30 AM Breakouts \#2

Steve Krueger -Entrainment and Mixing

Mark Miller - Precipitation

Entrainment: Bretherton, Burrows, Ghan, Ghate, Jensen, Krueger, Wood, Del Genio

Precip: Fridlind, Kollias, McGraw, Miller, Painemal, Russell, Wang, Yuter

3:30 - 3:45 PM Coffee Break (included)

3:45 - 4:15 PM Debrief

4:15 - 5:30 PM Group Discussion(s)

Identifying Measurement and Modeling Gaps/Needs

Field Campaign Needs

5:30 - 8:00 PM Dinner (offsite, not included)

Friday, January 29

$\begin{array}{ll}\text { 8:30 - 9:00 AM } & \text { Continental Breakfast (included) } \\ \text { 9:00- 9:30 AM } & \text { Review of Day 2 Discussions } \\ \text { 9:30-10:30 AM } & \text { Discussion of Outcomes and Recommendations } \\ \text { 10:30-10:45 AM } & \text { Coffee Break (included) } \\ \text { 10:45-11:30 AM } & \text { Discussion of Outcomes and Recommendations } \\ \text { 11:30- noon } & \text { Wrap-up } \\ \text { noon-1:15 } & \text { Lunch at Berkner (not included) }\end{array}$




\section{Appendix B: Participants}

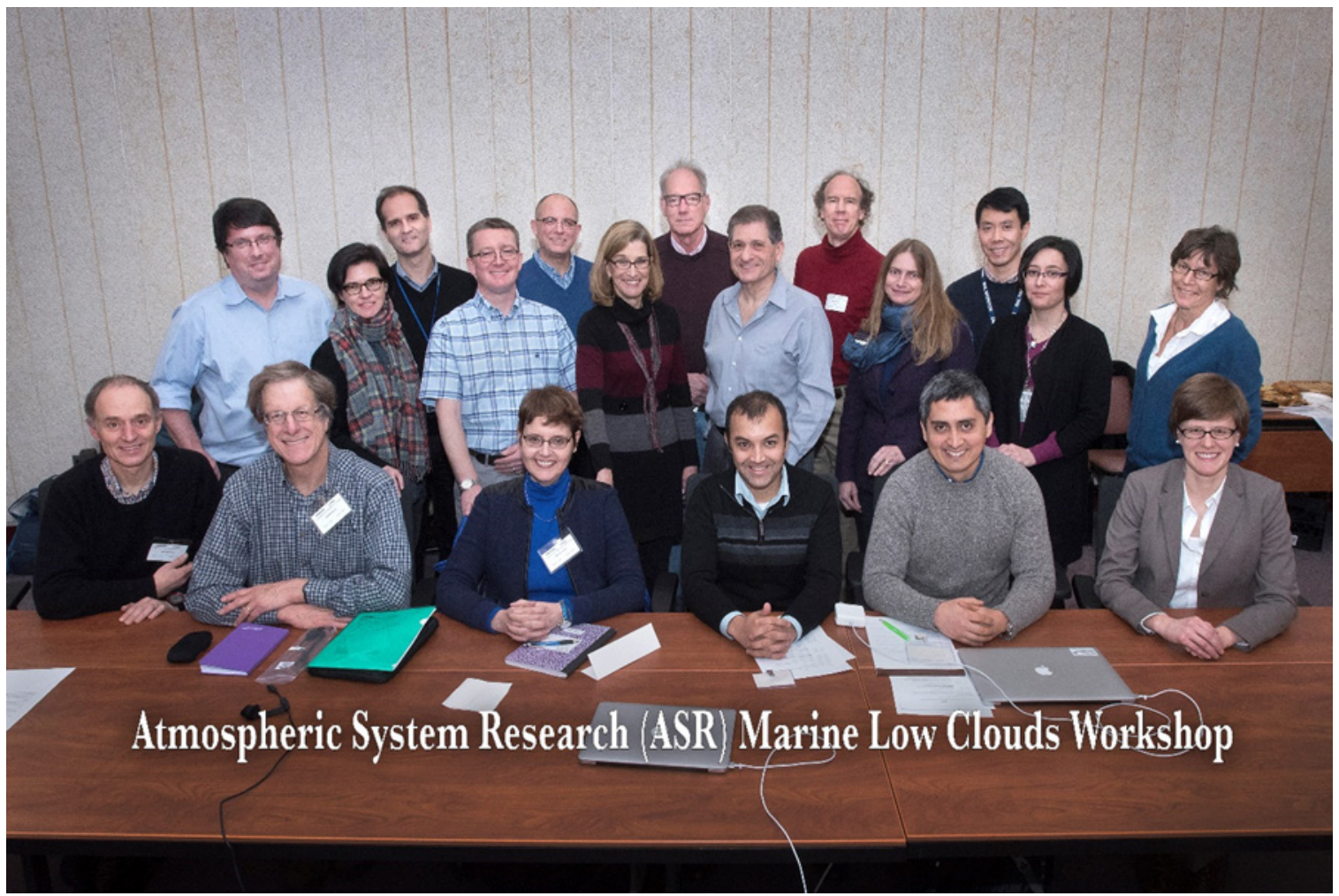

Figure 1. Front (L-R): Bretherton, Chris (U. of Washington), Steve Krueger (U. of Utah), Sandra Yuter (North Carolina State U.), Virendra Ghate (Argonne National Lab), David Painemal (NASA Langley), Susannah Burrows (Pacific Northwest National Lab). Back (L-R): Michael Jensen (Brookhaven National Lab), Ann Fridlind (NASA GISS), Pavlos Kollias (Stony Brook University), Rob Wood (U. of Washington), Mark Miller (Rutgers U.), Sharon Zuhoski (Brookhaven National Lab), Bob McGraw (Brookhaven National Lab), Tony Del, Genio (NASA GISS), Steve Ghan (Pacific Northwest National Lab), Lynn Russell (Scripps Oceanographic Institute), Jian Wang (Brookhaven National Lab), Shaima Nasiri (DOE ASR), Paquita Zuidema (U. of Miami). 